\title{
Trends and transitions in children's coresidence with older adults in Beijing municipality
}

\author{
Zachary Zimmer \\ Population Council \\ Xianghua Fang \\ Toshiko Kaneda \\ Population Council \\ Zhe Tang \\ Julia Kwong
}

Follow this and additional works at: https://knowledgecommons.popcouncil.org/departments_sbsr-pgy

Part of the Demography, Population, and Ecology Commons, Family, Life Course, and Society Commons, Gerontology Commons, and the International Public Health Commons How does access to this work benefit you? Let us know!

\section{Recommended Citation}

Zimmer, Zachary, Xianghua Fang, Toshiko Kaneda, Zhe Tang, and Julia Kwong. 2004. "Trends and transitions in children's coresidence with older adults in Beijing municipality," Policy Research Division Working Paper no. 187. New York: Population Council. 


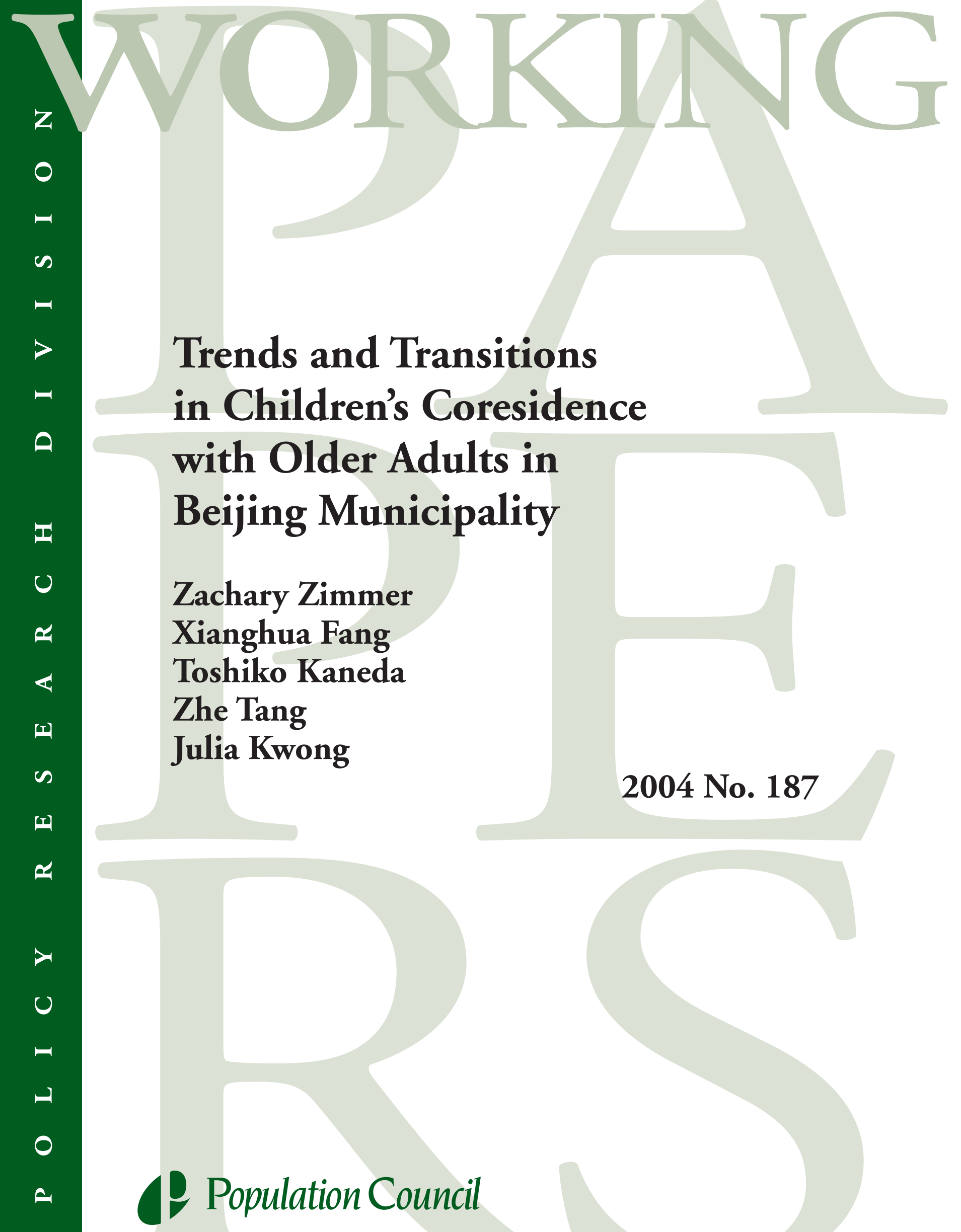




\title{
Trends and Transitions in Children's Coresidence with Older Adults in Beijing Municipality
}

\author{
Zachary Zimmer \\ Xianghua Fang \\ Toshiko Kaneda \\ Zhe Tang \\ Julia Kwong
}

Zachary Zimmer is Research Associate, Population Council. Xianghua Fang is Associate Professor, Capital University of Medical Science, Xuanwu Hospital. Toshiko Kaneda is Berelson Fellow, Population Council. Zhe Tang is Head and Director of Research, Capital University of Medical Science, Xuanwu Hospital. Julia Kwong is Professor of Sociology, University of Manitoba, Winnipeg, Canada.

This research is supported by a grant from the National Institute on Aging, Grant Number R01 AG20063-01.

This material may not be reproduced without written permission from the authors. For a list of Policy Research Division Working Papers, including those available for downloading in PDF format, see www.popcouncil.org/publications/wp/prd/rdwplist.html. 


\begin{abstract}
This paper examines a) whether rates of coresidence between older adults and their adult children in the Beijing municipality of China have been declining, and b) the determinants of coresidence and coresidence transitions. The reduction in family size in China and concurrent social and economic change are raising concerns that traditional sources of support may be eroding. Associations with family size and other determinants that fit within categories of availability and need for support, and demographic characteristics, are tested. Data come from a longitudinal study conducted in Beijing municipality, including urban Beijing and rural surroundings. Results suggest very moderate declines in coresidence of the elderly with children from 1992 to 1997. Family size is modestly associated with coresidence, but other determinants are stronger. The use of time-varying covariates in multi-wave transition modeling shows that changes in some characteristics related to the need for support - for instance, functional health - lead to changes in coresidence. Implications for old-age support within an aging China are discussed.
\end{abstract}


A principal concern of policymakers and others interested in the well-being of older adults in developing societies is the maintenance of material, physical, and psychological support in the face of declining family size and socioeconomic change (Hermalin and Myers 2002; Jones 1993; Martin 1988; Phillips 2000). In most of the developing world, adult children and other family members are considered to be the primary means of support for older adults. A customary system of coresidence between an older adult and a grown child is often thought to underpin this system (Asis et al. 1995; Bongaarts and Zimmer 2002; Knodel and Debavalya 1997; Logan, Bian, and Bian 1998; Sokolovsky 2001). But smaller family size, a consequence of ongoing fertility decline, may result in fewer available children with whom to coreside; and concurrent changes that accompany socioeconomic development can lead to higher rates of migration and to children's assertion of independence, thereby increasing the social, psychological, and physical distance between older adults and their offspring. Under these circumstances, a number of writers have expressed apprehension that the support needs of older adults living in societies experiencing rapid socio-demographic change will go unmet (Du and Guo 2000; Choi 2000).

We address these issues by examining recent trends in and determinants of coresidence and transitions in coresidence in China, a country experiencing rapid rates of aging and socioeconomic development. Reliance on cross-sectional data in most previous studies of this kind has limited tests of causal ordering (Brown et al. 2002). An advantage of a transition analysis such as ours, which requires panel data, is the ability to model coresidence state at present as a function of a set of determinants and a particular coresidence state measured earlier in time. We use three waves of survey data for this purpose and focus in particular on how changes in some time-varying determinants that relate to the support needs of older adults - for instance, health status - can trigger certain responses in coresidence transitions.

\section{POPULATION AGING, CORESIDENCE TRENDS, AND SUPPORT}

With about one-fifth of the world's population aged 60 years and older, China currently has the largest number of older adults (Du and Guo 2000). At the same time, this segment of the country's population is growing rapidly (Zeng and George 2001). About 7 percent of the population was aged 60 and older in 1950. The proportion has increased to about 10 percent today and is projected to reach about 30 percent by 2050 (United Nations 2002). The population aged 80 and older, nearly nonexistent in 1950 and at about 1 percent today, is expected to increase most rapidly (Zeng et al. 2002). The main cause of this alteration in age structure is the decline in fertility that has occurred over the past few decades (Poston and Duan 2000; Jiang and Zhang 2000). Total fertility rates exceeding six children per woman in the 1950s and 1960s have declined to under two births per woman today. Thus, individuals moving into older age brackets have fewer children than their 
predecessors, creating population aging at the country level and fewer children at the family level.

Much has been written about the normative role of filial piety in China and its relationship to child coresidence. Children are considered to be indebted to their parents and are obliged to secure the latter's well-being through the transfer of physical and material support (Whyte 2003; Yuan 1990). In Confucian writings, duty to and respect for parents is emphasized as a way of proving one's worthiness and of benefiting the family and society at large (Ebrey 1996). For a variety of reasons, it appears as if the changes in political structures that have occurred since 1949 have done little to reduce the responsibility that the family has in providing for the needs of older adults (Logan et al. 1998; Treas and Chen 2000; Whyte 2003). The role of the family has now been formalized into law, allowing for penalties to be imposed on those who do not adequately support elderly members of the family (Fricke, Chang, and Yang 1994; Leung 1997; Martin 1990).

Coresidence with adult children is considered the primary way in which contact is maintained and exchange of physical and material resources is facilitated. The role of coresidence in providing support for older Chinese has been verified in a number of studies (Knodel and Ofstedal 2002; Logan and Bian 1999; Logan et al. 1998; Pei and Pillai 1999; Whyte 1997; Whyte and Qin 2003; Yan, Chen, and Yang 2003; Yan and Chi 2001; Yuan 1990). Older adults in China tend to state a preference for living with a son, and subsequently a daughter-in-law is viewed as the family member most naturally disposed to providing daily assistance to older adults, while daughters are seen as being responsible for providing care for older adults of the family of their spouse (Logan and Bian 1999; Mason 1992). Hence, the availability of a married son is of particular importance, and parents with sons in Chinese societies have been found to be more likely to be in a coresident situation (Knodel and Ofstedal 2002; Logan et al. 1998). Yan et al. (2003) noted that parents who coreside with children receive more household help than do others, with parents living with a married son getting the most support, while Pei and Pillai (1999) suggested that parents with more children and those living with a son and daughter-in-law were happier than others.

The potential that socioeconomic change has for eroding traditional family values has been a long-standing concern (Cowgill and Holmes 1972). Modernization theorists have predicted that urbanization and industrialization alter living arrangements by 1) diminishing the authority of older persons and thus their ability to demand assistance from family members, 2) increasing the desire of children to live independently, and 3) transforming preferences of older adults so that they value daughters and sons equally (Goode 1963; Levy 1966). More recently, the reduction in family size has come to be regarded as the most foreboding aspect of the shifting social circumstances within China (Banister 1990; Cheung 1988; Hermalin and Myers 2002; Lin 1994; Zeng and George 2001; Zimmer and Kwong 2003). The swiftness of change has, at times, led to a type of "moral panic" regarding the possibility of unmet needs that could require public 
intervention of unprecedented magnitude (Du and Guo 2000; Phillips 2000). Whether or not alarm is justified, China clearly is experiencing an unprecedented growth in the numbers and proportion at older ages. And given that older adults are among those who generally require the greatest amount of support, current and future levels of care for older adults is considered one of the most important academic and policy concerns in China (Cheung 1988; Gui 2001; Pei and Pillai 1999).

Empirical evidence on the relationship between socioeconomic and demographic change and children's coresidence in the Chinese and Asian context shows variation in the practice. Rates of coresidence between an older adult and an adult child have fallen considerably in South Korea and Japan, and this decline is often attributed to changing values within a rapidly developing socioeconomic environment (Kim et al. 1996; Maeda and Shimizu 1992). At the same time, coresidence rates in these countries remain far above those in the West, and studies find a continued desire for coresidence on the part of parents (Budak, Liaw, and Kawabe 1996; Kim and Rhee 1999). Elsewhere in Asia, coresidence rates and related norms about traditional support roles of adult children have remained relatively stable (Asis et al. 1995; Knodel and Debavalya 1997; Knodel and Ofstedal 2002). Hashimoto (1991) has suggested that availability of children influences coresidence patterns differently in different countries. For Thailand, a country experiencing rapid fertility decline, Knodel, Chayovan, and Siriboon (1992) showed that rates of coresidence are not likely to decline in the future since parents with one or two children still coreside with a child. In other words, there may be no linear association between number of children and the chances of coresiding with at least one.

For China, Zeng $(1990,1986)$ proposes that the reduction in family size will lead to an increase in nuclear families. Du and Guo (2000) doubt whether current customs related to coresidence will survive and suggest that the departure from extended family living arrangements is already occurring. The decline in fertility, they say, has placed a heavier burden of old-age care on a smaller number of family members. Other studies are more sanguine, suggesting that coresidence with older adults and the resultant levels of support are not likely to fall sharply, or that such support may be facilitated through living near to but not in the same household as children (Lin 1994; Bian, Logan, and Bian 1998; Siriboon and Knodel 1994; Zimmer and Kwong 2003).

\section{DETERMINANTS OF CORESIDENCE WITH CHILDREN}

To develop a framework for studying coresidence with children, we draw on past research that has examined determinants of coresidence and other types of support indicators, either alone or together with coresidence, in China and a number of comparable developing societies (Albert and Cattell 1994; Anh et al. 1997; Budak et al. 1996; Cameron 2000; Chan 1997; DaVanzo and Chan 1994; De Vos 1998, 1990; Frankenburg, Chan, and Ofstedal 2002; Hermalin, Ofstedal, and Chang 1996; Knodel and Debavalya 1997; Knodel and Ofstedal 2002; Lee and Xiao 1998; Logan and Bian 1999; Logan et al. 1998; Martin 
1989; Natividad and Cruz 1997; Weinstein, Chang and Freedman 1994; Yan et al. 2003; Zeng and George 2001; Zimmer and Kim 2001; Zimmer and Kwong 2003). Although language and terminology differ among these studies, there is general agreement that determinants can be partitioned into those that generally relate to availability and those that generally relate to need. In addition, there are demographic characteristics that relate to the propensity of older adults to seek and obtain support. This terminology - availability, need, and propensity - borrows most directly from Knodel and Ofstedal (2002) and Zimmer and Kwong (2003), although it is also closely related to the notions of supply and demand adopted by DaVanzo and Chan (1994).

Availability refers to the presence and number of children with whom an older adult may coreside. The concern often expressed in the literature is that as the availability of children declines, so too does the tendency to coreside, leaving older adults to fend for themselves and creating a need for expensive social programs to compensate for losses of traditional means of support (Budak et al. 1996; Choi 2000). The hypothesis derived from this point of view is that reduced availability of children relates to a lower probability of coresiding.

Need refers to older adults' requirements for material, physical, and psychological support in order to sustain their daily survival. Material support may be more critical among those who have earned less throughout their lives, have limited or no pension, and otherwise have limited material resources. Hence, indicators of socioeconomic status would indicate level of need. Older adults who are in poor health require help in conducting functional tasks such as cooking, shopping, and moving about. This type of assistance may require closer proximity than material assistance, which can be remitted from a distance. The availability of a spouse may decrease this need since spouses are already likely to be providing assistance. If normative ideas about the family and its role in offering support to older adults are accepted, one would hypothesize that adults who have greater need would be more likely to coreside with children.

Studies that alternatively have examined needs and characteristics of children have indicated that these factors are also important for modeling coresidence (Frankenburg et al. 2002; Logan and Bian 1999). The data we use have limited information on characteristics of children, such as their age, education, and occupational status, and therefore we are unable to estimate their influence on coresidence. However, Logan et al. (1998) show that although children's needs are important to consider, it is mainly the needs of parents that underlie the propensity for coresidence. For instance, they found that when characteristics of adult children are controlled, frailer adults and widowed parents are much more likely to live with an adult child.

Demographic characteristics of families influence the ability or desire to seek coresidential living arrangements. For instance, in some societies females are viewed as more independent than males, being better able to cook and maintain a household; hence their desire for living with a child may be less than that of males. As adults age, so do their 
children, and the probability that children will marry and seek an independent household increases. A number of studies have related urban residence to higher rates of coresidence given the scarcity of housing in some cities and the related wish to share expensive living costs (De Vos 1990; Martin 1989; Zimmer and Kim 2001). Moreover, individual socioeconomic characteristics are strongly related to functional health (Huisman, Kunst, and Mackenbach 2003; Link and Phelan 1995; Preston and Taubman 1994). Age may indicate a need for assistance with daily living, since persons at older ages will generally have more health problems. Higher income might decrease the need for support, but those with higher income may also be in a better position to demand assistance from their children in exchange for material resources.

An additional consideration is that some of the determinants outlined above vary with time, and changes in these time-varying determinants may elicit certain changes in living arrangement. Most studies have been unable to speculate on these "transitional" effects since data used to examine living arrangements tend to be cross-sectional (Brown et al. 2002). Given the panel data we use in our study, we can identify three types of changes that may affect coresidence: health, marital status, and income. Each of these can increase, or for that matter decrease, the need for support. For instance, an older adult may develop chronic health disorders or experience improvement or deterioration in functional capacity, thus changing their need for daily assistance in carrying out functional tasks (Crimmins and Saito 1993). A spouse may die, leaving an older adult without coresidential sources of support; an older adult may remarry, thereby decreasing his or her need for additional assistance; or an older adult may stop or start working for pay, thus changing his or her material needs. Hence, we can hypothesize that elderly parents who do not coreside with a child and who experience a deterioration in health, loss of a spouse, or loss of income will be more likely than others to coreside with one or more children after the change in need has occurred. Alternatively, becoming healthier, gaining a spouse, or gaining income should have the opposite effect.

\section{A STUDY OF CORESIDENCE IN BEIJING}

\section{Data}

We examine trends and transitions in coresidence with children, using data from the first three waves of the Beijing Multidimensional Longitudinal Study on Aging. This study, which is planned, administered, and carried out under the direction of Zhe Tang of the Capital University of Medical Science in Beijing, involves a series of panel surveys of individuals who were aged 55 and older in 1992. Its purpose is to analyze population aging in the Beijing municipal area with specific reference to societal, cultural, economic, functional, and environmental influences. The three waves of data were collected in 1992, 1994, and 1997. A 2000 follow-up was conducted, but the questionnaire in that year did not include a number of items necessary for inclusion in the current analysis. 
Beijing municipality, where the study takes place, includes 18 administrative areas (called districts in metropolitan areas and counties in rural areas) within three geographic regions: metropolitan Beijing ( 8 districts), rural plains (5 counties), and rural mountains (5 counties). Some rural counties are more than 100 kilometers from the metropolitan districts. Sampling for the study began by choosing one area from each of the three regions: Xuan Wu (Beijing), Da Xing (rural plains), and Huai Ruo (rural mountains). These were chosen on the basis of their representativeness within the Beijing municipal region with respect to a number of socioeconomic and demographic characteristics. The initial 1992 sample included 3,257 individuals, and the response rate was 90 percent. Subsequent waves involved returning to original households. Nonrespondents included those who moved out of the area in which they were originally interviewed, and those who otherwise could not be found. Survival was determined through interviews with those still living in the household or others living nearby. A nonresponse in the second wave did not mean a nonresponse in the third, as third-wave re-interviews were attempted for all original respondents deemed to have survived. The second and third waves had a combined response rate of 90 percent. Older individuals and those living in metropolitan Beijing were oversampled, but a weighting scheme was established so that the final sample is representative based on age, sex, and within-county population. (Details on the data and the sampling techniques can be found in Department of Social Medicine 1995; Jiang et al. 2002; Tang et al. 1999.)

Our analysis includes respondents reporting having at least one living child. Childlessness is uncommon in China, and this criterion reduces the initial sample to 3,104. Because the current analysis considers transitions across time, those who did not respond in Wave 2 must be considered as nonrespondents for Wave 3 even if they reentered the sample. Figure 1 shows the number of individuals who responded, died, or survived but did not respond. In total, 1,951 individuals survived the observation period and responded at each wave.

Although response rates are high, it is probable that nonrespondents are a select group differing with respect to important social and demographic characteristics from those who do respond. To account for nonrandom nonresponse when estimating coresidence rates, we conducted an additional weighting procedure that adjusted for nonresponse in the second and third waves. This weighting involved calculating an adjustment factor based on the inverse of the probability that an individual with a specific set of characteristics responded to the survey. The characteristics used included sex, age, rural/urban residence, health, marital status, and living arrangement. Because of the rapid changes occurring in the metropolitan area of Beijing, respondents originally living in Xuan $\mathrm{Wu}$ were more likely to move during the course of the three waves than those originating in Da Xing or Huai Ruo; and, as such, rural/urban residence is by far best able to distinguish responders from nonresponders. Thus, elderly individuals from Xuan $\mathrm{Wu}$ were more likely than others to be nonrespondents, hence their weights are adjusted upward. 
Figure 1 Number of respondents, nonrespondents, and deaths in the Beijing Multidimensional Longitudinal Study on Aging ${ }^{\mathrm{a}}$

Wave 1: $1992 \quad$ Wave 2: $1994 \quad$ Wave 3: 1997

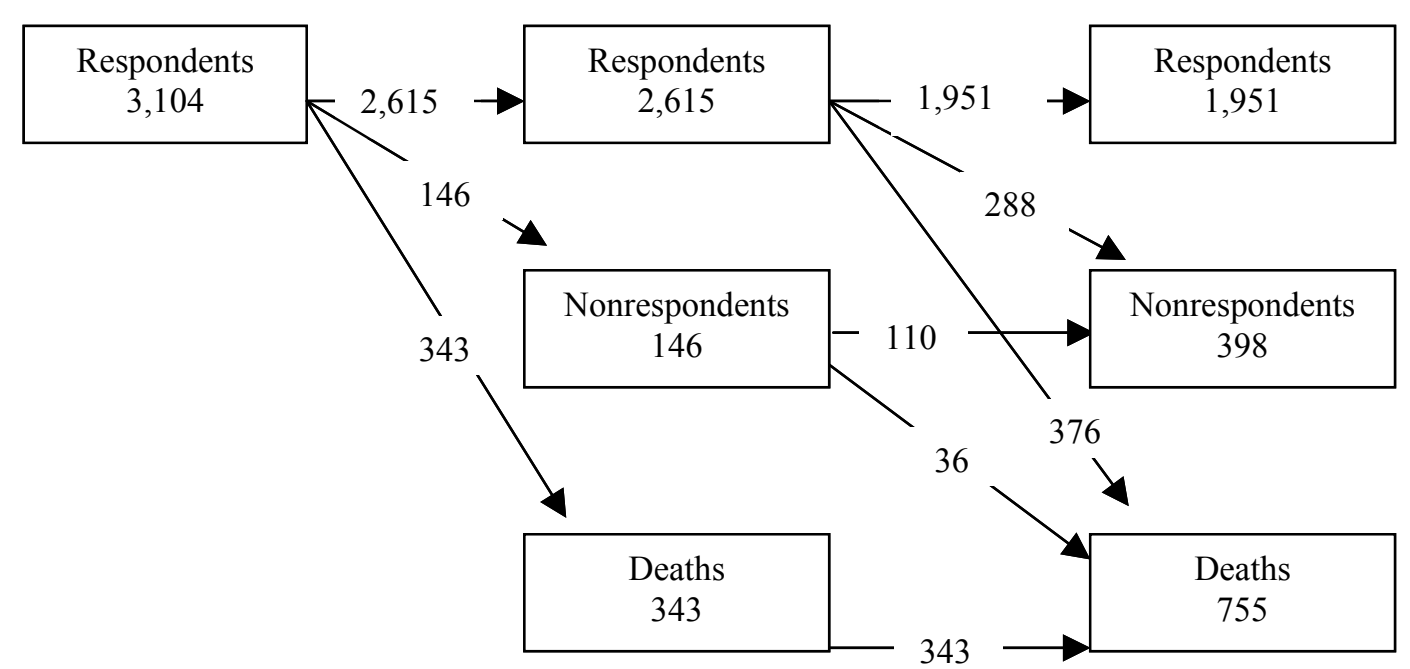

\footnotetext{
${ }^{a}$ Numbers omit 153 respondents reporting no living children at any time during the observation period; 40 individuals who were nonrespondents at Wave 2 but reentered the sample at Wave 3 are still considered nonrespondents at Wave 3.
}

\section{Measures}

The living arrangement of interest in our study is coresidence with at least one child. Information on this topic was provided through the use of a household roster administered to each respondent at each wave. Those living with a child are coded as 1 and others as 0 .

Covariates used in multivariate equations include those representing categories of availability, need, and demographic characteristics. The availability category includes measures of number of living children and the presence of a son. Number of children is categorized into $1,2,3,4,5$, and 6 or more. For estimation purposes, we create a series of dichotomous variables that contrast having one versus having other numbers of children. Treating number of children categorically is necessary since effects may be nonlinear and there may be thresholds above which having additional children does not make a difference. Having a son is coded 1 , and those without sons are coded as 0 . 
The need category includes two measures of health, three measures of socioeconomic status, and a single measure of whether an individual lives with a spouse (coded 1 if a spouse is present in the household and a 0 if not). This indicator is a proxy for marital status, but it relates more directly to need since it is possible for a spouse to be living elsewhere.

The first health measure is a single dichotomous indicator for whether individuals report a functional limitation or difficulty with an activity of daily living (Katz et al. 1963), that is, an inability to perform one of the following functional tasks: eating, grooming, dressing, getting in and out of bed, bathing, moving around the house, cooking, managing money, shopping, walking 300 meters outside, and walking up and down a flight of stairs. Those who have such limitations are likely to be in greater need of assistance in conducting daily tasks. The second measure is the existence of a chronic condition. Respondents were read a list of health conditions and asked whether they have ever had any of these: stroke, arthritis, glaucoma, cataract, coronary heart disease, chronic bronchitis, and emphysema. We consider an affirmative response to any one of these as indicating a chronic health condition. There are two difficulties in using this measure. First, many chronic health conditions are asymptomatic and may require extensive medical examinations to be identified. Regular medical exams are not conducted routinely in China, particularly among those living in rural areas. Second, individual conditions relate to differing levels of need. Someone with arthritis, for instance, may require physical assistance much more regularly than someone with coronary heart disease, even though the latter is potentially a more life-threatening condition. It is difficult, however, to analyze the influence of chronic conditions individually given the current sample size. We therefore advise caution when interpreting our results.

The first socioeconomic characteristic is education, coded as having or not having any formal schooling. The second is whether older adults themselves receive any income from work or a pension. Specific occupational codes are difficult to determine with our data, but two survey questions asked respondents to classify broadly the occupation they had had for most of their lives (for example, professional, administrator, agricultural worker), and whether this occupation included heavy labor. We dichotomize the measure by first separating the "white-collar" occupations from others, then determining whether the non-white-collar occupation involved heavy labor. We refer to this measure with the terms heavy and non-heavy-labor occupations. Some individuals indicated that their occupation for most of their lives was housework. These individuals were also asked the question about heavy labor and thus are included in one of these two categories. Labor force participation rates are relatively high for women in China, and only about one-quarter reported housework as their occupation.

Demographic characteristics include sex (with females coded as 1), rural/urban residence (with rural coded as 1), and five age categories (55 to 59, 60 to 64, 65 to 69,70 to 
74, and 75 and older). Multiple categories of age are used because the probability of receiving support is not likely to be linear with increasing age.

Table 1 provides descriptive information on covariate measures included in the study for the three waves, using the original weights for Wave 1 and weights adjusted for nonresponse for Waves 2 and 3 .

Table 1 Descriptive information for covariates (percent)

$\begin{array}{ccc}\text { Wave 1 } & \text { Wave 2 } & \text { Wave 3 } \\ 1992 & 1994 & 1997\end{array}$

\section{Availability of support}

Number of living children

1

2

3

4

5 or more

$\begin{array}{rrr}5.8 & 5.8 & 5.6 \\ 15.9 & 15.9 & 16.5 \\ 22.1 & 22.6 & 21.9 \\ 23.4 & 23.7 & 24.9 \\ 32.9 & 31.9 & 31.0 \\ 92.4 & 92.6 & 92.4\end{array}$

Has a living son

\section{Need for support}

Health

Has functional limitation or disability

$\begin{array}{lll}10.6 & 8.8 & 14.5\end{array}$

Has chronic condition

35.2

39.2

55.4

Socioeconomic characteristics

Has some formal education

$50.4 \quad 51.6 \quad 53.6$

Receives income from work or pension

$64.9 \quad 59.6 \quad 64.2$

Lifetime work was non-heavy-labor occupation

$\begin{array}{lll}43.7 & 44.4 & 46.1\end{array}$

Lives with spouse

$\begin{array}{lll}77.0 & 75.2 & 73.2\end{array}$

Demographic characteristics

Age

55 to 59

60 to 64

65 to 69

70 to 74

75 and older

Female

Lives in rural area

\begin{tabular}{rrr}
32.1 & 18.3 & 0.0 \\
24.6 & 31.7 & 36.2 \\
18.4 & 19.7 & 26.3 \\
12.1 & 15.2 & 18.2 \\
12.9 & 15.1 & 19.2 \\
50.6 & 51.3 & 51.0 \\
49.8 & 48.5 & 47.0 \\
3,104 & 2,615 & 1,951 \\
\hline
\end{tabular}




\section{Analytical techniques}

Our analysis proceeds in two stages. In the first, we examine trends in coresidence with children by indicating the percent of individuals living with a child over the three waves. To adjust for changes in population composition over time and to examine determinants of coresidence from cross-sectional data, we conduct a logistic regression that pools data across the three waves and controls for the covariates discussed above, entering observation year into the equation. If changes have occurred in child-coresidence trends, then the coefficient for the observation year will be significant. The outcome of interest for this procedure is whether an older adult lived with a child in the year of observation. The total pooled sample size is 7,670 . This procedure considers robust standard errors that adjust for multiple observations of the same individuals over time.

In the second stage, we examine a three-wave logistic regression model of transitions in coresidence with children. The outcome is child-coresidence status at Wave 3 , and we examine associations with characteristics observed at baseline (Wave 1) and, where appropriate, Wave 2. The addition of coresidence status in Waves 1 and 2 means that these results can be interpreted as effects of the covariates on changes in coresidence over time (Brown et al. 2002). This procedure includes only those persons surviving and responding to all three waves. As we mentioned above, however, a certain proportion of the baseline sample will not survive or will be lost, and deaths and losses are not random. Hence, we also conduct a multinomial logistic regression to show how the covariates are associated with competing risks of dying versus surviving and responding and surviving and not responding.

One of the advantages of the multi-wave approach for analyzing transitions is that it allows us, with greater causal certainty, to examine whether changes in some determinants at an earlier point in time induce changes in coresidence with children. For instance, we would expect that individuals who are healthy at the first wave but unhealthy at the second have a greater chance of moving in with a child if they do not coreside with one already, or a greater chance of continuing to live with a child if they live with one already. Hence, the multi-wave analysis considers two types of determinants: those that remain stable over time, like education and sex, which are measured at baseline only; and those that are at risk of changing over time, like health and coresidence with a spouse, which are measured at both Waves 1 and 2. For instance, an individual may have no functional limitations at Wave 1 but may report limitations at Wave 2; both of these covariates are included in the transition model. Because we control for coresidence status at Waves 1 and 2, we can determine what effect the change in functional limitation has on the probability of changing coresidence status. Because change in time-varying covariates can generally be in two directions (except for chronic conditions, an incidence measure), we tested for interaction effects between the determinant at Waves 1 and 2. None of these effects was significant, indicating that the effect on coresidence is similar regardless of the direction of change in time-varying covariates. 


\section{RESULTS}

\section{Trends and cross-sectional determinants of coresidence with children}

Table 2 shows distributions of coresidence with children across waves (1992, 1994, and 1997). The first row indicates the percent of elderly parents living with at least one child. This proportion declines from 64 percent at Wave 1 to 57 percent by Wave 3, a statistically significant change. Since mortality is not random, however, and since those in the sample aged over time, it is quite possible that there were changes in the characteristics of older adults that subsequently relate to coresidence and that might account for the decline. To illustrate the point, the table shows the percent coresiding in the three years by demographic characteristics. The decline in coresidence remains evident across categories of sex and residence. The same is not true for age. By Wave 2 the sample is aged 57 and older and by Wave 3 it is aged 60 and older; so the decline in coresidence from Wave 1 to Wave 2 exhibited by the 55-to-59-year age group may not reflect a true change in coresidence over time due to within-category aging. That is, in 1994 the age of this group is older than it was in 1992, and by 1997 everyone has aged out of the group. So, the Wave 1 versus Wave 2 comparison does not adjust for age, and we cannot make a comparison for this age group to Wave 3. However, within other age groups, there is no statistically significant decline.

Table 2 Trends in coresidence with children, showing coresidence distributions across waves for the total sample and by demographic characteristics (percent)

\begin{tabular}{|c|c|c|c|c|}
\hline & $\begin{array}{c}\text { Wave } 1 \\
1992 \\
\end{array}$ & $\begin{array}{c}\text { Wave } 2 \\
1994\end{array}$ & $\begin{array}{c}\text { Wave } 3 \\
1997\end{array}$ & Significance $^{\mathrm{a}}$ \\
\hline $\begin{array}{l}\text { Coresides with at least } \\
\text { one child }\end{array}$ & 64.0 & 60.6 & 56.5 & $* *$ \\
\hline \multicolumn{5}{|l|}{ Coresidence by sex } \\
\hline Male & 63.8 & 59.5 & 54.6 & $* *$ \\
\hline Female & 64.2 & 61.7 & 58.4 & $* *$ \\
\hline \multicolumn{5}{|l|}{ Coresidence by age } \\
\hline 55 to 59 & 73.4 & 67.0 & --- & $* *$ \\
\hline 60 to 64 & 63.2 & 60.3 & 58.1 & Ns \\
\hline 65 to 69 & 55.7 & 54.5 & 55.1 & Ns \\
\hline 70 to 74 & 55.0 & 56.7 & 49.4 & Ns \\
\hline 75 and older & 62.4 & 65.7 & 62.1 & Ns \\
\hline \multicolumn{5}{|l|}{ Coresidence by residence } \\
\hline Rural & 62.5 & 58.7 & 57.9 & $*$ \\
\hline Urban & 65.5 & 62.5 & 55.3 & $* *$ \\
\hline
\end{tabular}


Table 3 presents the results of logistic regressions predicting coresidence with children at a given point in time using pooled cross-sectional data. Shown here are log odds ratio coefficients. The significant bivariate associations between year of observation and living with children seen in Table 2 are mostly accounted for by the addition of covariates. There is virtually no significant decline in coresidence between Waves 1 and 2, and there is a slight decline between Waves 1 and 3 that is significant at a .10 level.

As for the cross-sectional determinants of coresidence, we find some association with number of children. Specifically, elderly individuals with two or three children are more likely to be living with a child than are those with one. But, the chances of living with a child do not increase for those with more than two children. In fact, there appears to be a slight, though insignificant, decline in coresidence for those having more than three children. This pattern suggests that having two living children maximizes the chances of coresidence at any given time. Having a son is positively associated with coresidence, although the magnitude of the coefficient is small and the result is not statistically significant. The bivariate association between having a son and coresidence is somewhat larger, but the effect becomes minimal when account is taken of other covariates. Nevertheless, this result is contrary to expectations.

The need characteristics are generally related to likelihood of coresidence in expected directions. The elderly with functional disabilities are more likely than those functionally healthy to be living with a child. Converting the log odds ratios shown in the table to odds ratios, we observe that having a functional limitation increases the chances of living with a child by a factor of $\mathrm{e}^{.278}$ or about 32 percent. Chronic conditions have no significant effect on likelihood. Those with education, receiving income, and whose main occupation did not involve heavy labor are less likely than others to be living with a child at any given time, although the education coefficient is not statistically significant. Finally, those living with a spouse are much less likely to coreside with a child. Overall, then, the results indicate that the elderly with greater need are more likely to be coresiding with a child.

The demographic characteristics are significant. An increase in age lowers the chances of living with a child, although the effect levels off after age 70 . The leveling off at older ages is likely due to the association between the age of the older adult and the age of their children. That is, the older the child, the greater the probability that he or she will marry and perhaps the greater the tendency to seek independence (Casterline et al. 1991). The greatest chance of living with a child exists among those 55 to 59 years of age. Females and those in rural areas are less likely than are males and those in urban areas to live with a child. 
Table 3 Determinants of living with children at Waves 1, 2, and 3, showing log odds ratios $(\mathrm{N}=7,670)$

\section{Log Odds \\ Coefficient}

\section{Year of observation or year of original observation}

(Wave 1, 1992, is comparison)

Wave 2 (1994)

Wave 3 (1997)

$-.073$

$-.110^{\wedge}$

\section{Availability of support}

Number of living children (comparison is 1 child)

$\begin{array}{ll}2 & .320^{\wedge} \\ 3 & .332^{*} \\ 4 & .190 \\ 5 \text { or more } & .236 \\ \text { Has a living son } & .018\end{array}$

\section{Need for support}

Has functional limitation or disability

Has chronic condition

$-.107$

Has some formal education

$-.176$

Receives income from work or pension

$-.264 * *$

Lifetime work was non-heavy-labor occupation

$-.291 * *$

Lives with spouse

$-1.028^{* *}$

\section{Demographic characteristics}

Age (comparison is 55-59 years)

60 to 64

65 to 69

70 to 74

75 and older

Female

Lives in rural area

$-.506^{* *}$

$-.823^{* *}$

$-1.016^{* *}$

$-1.004 * *$

$-.228^{*}$

$-.590^{* *}$

Constant

LL

Model $\chi^{2}$ 


\section{Transitions in coresidence with children}

Table 4 shows the percent of respondents coresiding with a child at Wave 3 by coresidence status at Waves 1 and 2. For instance, the first column indicates that 1,020 individuals were coresiding with at least one child at both Waves 1 and 2. Among those who survived, 83 percent were still coresiding at Wave 3 while the other 17 percent changed coresidence status. The second column shows that among the 584 individuals who did not coreside at either Waves 1 or 2, 14 percent changed status. The last two columns present results for those who experienced a change of status between Waves 1 and 2. They indicate that these individuals were more likely to change coresidence status between Waves 2 and 3 than were those whose status was stable between Waves 1 and 2. In total, about 31 percent of individuals changed coresidence status at least once between Waves 1 , 2 , and 3, suggesting a fair amount of fluidity in coresidence with children. Of course, this pattern can only be an underestimate of the actual number of changes taking place since we observe coresidence status at a limited number of fixed points in time. Also shown are distributions of competing risks by coresidence status at Waves 1 and 2 . The most striking finding here is that those who moved from not coresiding at Wave 1 to coresiding at Wave 2 were the group most likely to have died prior to Wave 3. Specifically, 14 percent of these individuals did not survive. In contrast, only 7 percent of those who moved from coresiding to not coresiding, and between 9 percent and 10 percent of those whose coresidence status was stable between Waves 1 and 2, did not survive. These numbers might suggest that a change in coresidence is prompted by poor health and the need to be cared for in the final years of life. In addition, those moving from coresidence to noncoresidence are likely to be a younger group of individuals at lower risk of dying.

Table 5 presents the results of the transition analysis and competing risks. For the first column of results, the outcome is living with a child at Wave 3. The results are logistic regression log odds coefficients for covariates measured at Wave 1 and, for variables that may change over time, at Wave 2. Although individuals age as time passes, everyone ages by the same amount, and therefore age is measured at Wave 1 only. In addition, we control for coresidence status at Waves 1 and 2. Controlling for earlier coresidence status allows us to interpret coefficients as effects on transitions in coresidence. For instance, for an individual who did not coreside at Wave 1 or Wave 2, the coefficient tells us about the influence of a covariate on the probability of living with a child at Wave 3, which is also the probability of making a change in coresidence status. In a similar fashion, for an individual who did coreside at Waves 1 and 2, the coefficient tells us about the probability of remaining in a coresident status. For covariates that do not change over time, such as education, the results can be interpreted as the effect of the characteristic measured at Wave 1 or Wave 2 (since the characteristic is constant) on transitions in coresidence status. For covariates that can change, the result can be interpreted as the effect of the characteristic at Wave 2 adjusted for the characteristic at Wave 1. In addition, the time-varying effects are additive. For instance, the first column of the table shows that the effect of having a 
functional limitation at Wave 2 on coresidence at Wave 3 for those without a limitation at Wave 1 is .863 . The effect of having a functional limitation at Wave 2 for those with a limitation at Wave 1 is $.863+.351=1.214$.

Table 4 Transitions in coresidence with children, showing coresidence distributions at Wave 3 (1997) by coresidence status at Waves 1 and 2 (1992 and 1994) and competing risks by coresidence status Waves 1 and 2 (percent)

\begin{tabular}{|c|c|c|c|c|c|}
\hline \multirow[t]{2}{*}{ STATUS $\rightarrow$} & WAVE 1 & $\begin{array}{r}\text { Coresides } \\
\text { with } \\
\text { child }\end{array}$ & $\begin{array}{c}\text { Does not } \\
\text { coreside }\end{array}$ & $\begin{array}{r}\text { Coresides } \\
\text { with } \\
\text { child }\end{array}$ & $\begin{array}{l}\text { Does not } \\
\text { coreside }\end{array}$ \\
\hline & WAVE 2 & $\begin{array}{r}\text { Coresides } \\
\text { with } \\
\text { child } \\
(\mathbf{N}=1,020)\end{array}$ & $\begin{array}{l}\text { Does not } \\
\text { coreside } \\
(N=584)\end{array}$ & $\begin{array}{r}\text { Does not } \\
\text { coreside } \\
(N=192)\end{array}$ & $\begin{array}{r}\text { Coresides } \\
\text { with } \\
\text { child } \\
(\mathrm{N}=155)\end{array}$ \\
\hline \multicolumn{6}{|c|}{$\begin{array}{l}\text { Among survivors responding at } \\
\text { Wave } 3\end{array}$} \\
\hline \multicolumn{2}{|c|}{ Lives with at least one child } & 83.1 & 13.6 & 39.6 & 53.3 \\
\hline \multicolumn{2}{|c|}{ Does not live with children } & 16.9 & 86.4 & 60.4 & 46.7 \\
\hline \multicolumn{6}{|c|}{ Competing risks } \\
\hline \multicolumn{2}{|c|}{ Survived and responded at Wave 3} & 82.0 & 81.1 & 80.6 & 78.4 \\
\hline \multicolumn{2}{|c|}{ Died prior to Wave 3} & 9.7 & 9.0 & 6.8 & 13.6 \\
\hline \multicolumn{2}{|c|}{$\begin{array}{l}\text { Survived but did not respond at } \\
\text { Wave } 3\end{array}$} & 8.3 & 9.9 & 12.6 & 8.0 \\
\hline
\end{tabular}

The other two columns show the multinomial results for competing risks. Here we show the log odds effects of covariates on the probability of dying versus responding at Wave 3 and of not responding versus responding at Wave 3 .

Whereas having two or more children was shown to increase the chances of coresiding at a given point in time, number of children does not significantly influence coresidence transitions, although it is clear from the coefficients that individuals with three children still have the greatest chance of coresiding with a child by Wave 3. Having a son, however, decreases these chances. 
Table 5 Determinants of transitions in coresidence with children $(\mathrm{N}=1,951)$ and competing risks $(\mathrm{N}=2,615)$, showing log odds ratios

\begin{tabular}{|c|c|c|c|}
\hline & \multirow[b]{2}{*}{$\begin{array}{c}\text { Effects on } \\
\text { Living with } \\
\text { a Child at } \\
\text { Wave } 3\end{array}$} & \multicolumn{2}{|c|}{ Competing Risks } \\
\hline & & $\begin{array}{c}\text { Dying } \\
\text { versus } \\
\text { Responding } \\
\text { at } \\
\text { Wave } 3\end{array}$ & $\begin{array}{c}\text { Not responding } \\
\text { versus } \\
\text { Responding } \\
\text { at } \\
\text { Wave } 3\end{array}$ \\
\hline \multicolumn{4}{|l|}{ Availability of support } \\
\hline \multicolumn{4}{|l|}{$\begin{array}{l}\text { Number of living children } \\
\text { (comparison is } 1 \text { child) }\end{array}$} \\
\hline 2 & .256 & -.506 & -.027 \\
\hline 3 & .401 & -.211 & -.044 \\
\hline 4 & .212 & -.248 & -.298 \\
\hline 5 or more & -.038 & -.232 & -.248 \\
\hline Has a living son & $-.471^{\wedge}$ & -.164 & .078 \\
\hline \multicolumn{4}{|l|}{ Need for support } \\
\hline $\begin{array}{l}\text { Has functional limitation or } \\
\text { disability at Wave } 1\end{array}$ & .351 & .317 & -.227 \\
\hline $\begin{array}{l}\text { Has functional limitation or } \\
\text { disability at Wave } 2\end{array}$ & $.863 * *$ & $1.272 * *$ & .406 \\
\hline Has chronic condition at Wave 1 & .172 & -.428 & .043 \\
\hline Has chronic condition at Wave 2 & -.404 & $1.073 * *$ & -.294 \\
\hline Has some formal education & -.301 & -.183 & .063 \\
\hline $\begin{array}{l}\text { Receives income from work or } \\
\text { pension at Wave } 1\end{array}$ & -.037 & -.389 & -.475 \\
\hline $\begin{array}{l}\text { Receives income from work or } \\
\text { pension at Wave } 2\end{array}$ & $-.530^{*}$ & -.245 & -.192 \\
\hline $\begin{array}{l}\text { Lifetime work was non-heavy- } \\
\text { labor occupation }\end{array}$ & $-.410^{*}$ & $-.455^{*}$ & -.235 \\
\hline Lives with spouse at Wave 1 & .096 & .419 & $.805^{*}$ \\
\hline Lives with spouse at Wave 2 & $-.719^{*}$ & $-.890 * *$ & $-1.324 * *$ \\
\hline \multicolumn{4}{|l|}{ Demographic characteristics } \\
\hline \multicolumn{4}{|l|}{ Age (comparison is $55-59$ years) } \\
\hline 60 to 64 & $.353^{\wedge}$ & .562 & -.065 \\
\hline 65 to 69 & .137 & $.797 *$ & -.134 \\
\hline 70 to 74 & $.374^{\wedge}$ & $.939 * *$ & -.009 \\
\hline 75 and older & $.586^{*}$ & $1.693 * *$ & .038 \\
\hline Female & -.083 & $-.681 * *$ & -.025 \\
\hline Lives in rural area & -.218 & -.319 & $-1.477 * *$ \\
\hline Lives with at least one child at Wave 1 & $1.560 * *$ & -.205 & .134 \\
\hline Lives with at least one child at Wave 2 & $2.076^{* *}$ & .142 & $-.523 * *$ \\
\hline Constant & -1.135 & -2.382 & -2.009 \\
\hline LL & -878.3 & \multicolumn{2}{|c|}{-1398.1} \\
\hline Model $\chi^{2}$ & $430.5 * *$ & \multicolumn{2}{|c|}{$379.2 * *$} \\
\hline
\end{tabular}

Notes: Chronic conditions can change in only one direction because the measure is incidence. Covariates that are not measured at both Wave 1 and Wave 2 are measured at Wave 1.

$* * \mathrm{p}<.01 \quad * .01<\mathrm{p}<.05 \quad \wedge .05<\mathrm{p}<.10$ 
The characteristics related to the need for support again are generally associated with coresidence in the direction expected, although fewer characteristics are significant. Functional limitations, chronic conditions, receipt of income, and living with a spouse are time-varying. Individuals with functional limitations at Wave 2 have a much higher probability of living with a child at Wave 3 after accounting for functional limitation status at Wave 1 and previous coresidence status. Similarly, those receiving income at Wave 2 are much less likely to live with children than those who are not. Elderly individuals living with a spouse at Wave 2 are much less likely to live with children at Wave 3. Of the timevarying covariates, only having a chronic condition is not significant. Although education is not significantly associated with coresidence status at Wave 3, the effect is in the expected direction. Those whose lifetime work was in non-heavy-labor occupations are, however, significantly less likely to coreside at Wave 3 after accounting for earlier coresidence status. These results again suggest that need for support is most strongly associated with both coresidence and transitions in coresidence over time, with those in greater need being more likely to live with and move in with children.

Although the effects of the demographic characteristics are weaker when it comes to transitions than they were in the cross-sectional results, some age effects remain, with those in the oldest age group being most likely to live with a child at Wave 3 after accounting for earlier coresidence status. Of course, residence status at Waves 1 and 2 is highly associated, with those who coresided earlier being most likely to remain coresident at Wave 3 , as was seen in Table 4 .

Analysis of competing risks show that individuals with functional limitations and chronic conditions are more likely to have died than were their healthier counterparts. Those with lifetime non-heavy-labor occupations and those living with a spouse at Wave 2 are significantly less likely to have died. Higher age is associated with a greater chance of dying, while women are more likely to survive than men. Only three covariates are significantly associated with nonresponse. When controlling for coresidence with spouse at Wave 1, those living with a spouse at Wave 2 are less likely to be nonrespondents at Wave 3 than are those not living with a spouse at Wave 2. Rural residents and those living with children at Wave 2 are also more likely to respond to the Wave 3 survey.

In Table 6 we present a more intuitive interpretation of the influence of changes in need on changes in coresidence status. We show selected predicted probabilities, calculated by using coefficients from Table 5, highlighting effects of the three time-varying covariates that were found to be significant, holding other things constant. The upper part of the table shows probabilities for those coresiding with a child at both Waves 1 and 2. The probabilities shown are for living with a child at Wave 3, hence the upper part indicates the chance of maintaining this living arrangement over time. For instance, among those who have no limitations at either Wave 1 or 2, the probability of maintaining coresidence with a child by Wave 3 is .832 . However, the probability increases to .919 among those who changed functional status from no limitations to limitations. In other words, becoming 
functionally limited over time increases the probability of remaining in a coresident living arrangement. In the same fashion, losing income and losing a spouse between Waves 1 and 2 increase the probability of continuing to live with a child by Wave 3 .

Table 6 Predicted probability of living with a child at Wave 3 by coresidence status at Waves 1 and 2 and selected time-varying characteristics at Waves 1 and 2, holding other covariates constant

\begin{tabular}{|c|c|c|c|}
\hline $\begin{array}{l}\text { Coresidence status at } \\
\text { Waves } 1 \text { and } 2\end{array}$ & $\begin{array}{c}\text { Wave 1 } \\
\text { Characteristic }\end{array}$ & $\begin{array}{c}\text { Wave } 2 \\
\text { Characteristic }\end{array}$ & $\begin{array}{c}\text { Predicted } \\
\text { probability } \\
\text { of coresiding } \\
\text { with a child } \\
\text { at } \\
\text { Wave } 3 \\
\end{array}$ \\
\hline \multicolumn{4}{|l|}{$\begin{array}{l}\text { Coresides with child at } \\
\text { both waves }\end{array}$} \\
\hline & $\begin{array}{l}\text { Has no functional } \\
\text { limitation or disability }\end{array}$ & $\begin{array}{l}\text { Has no functional } \\
\text { limitation or disability }\end{array}$ & .832 \\
\hline & & $\begin{array}{l}\text { Has functional limitation } \\
\text { or disability }\end{array}$ & .919 \\
\hline & $\begin{array}{l}\text { Receives income from } \\
\text { work or pension }\end{array}$ & Receives income & .819 \\
\hline & & Receives no income & .883 \\
\hline & Lives with spouse & Lives with spouse & .822 \\
\hline & & $\begin{array}{l}\text { Does not live with } \\
\text { spouse }\end{array}$ & .902 \\
\hline & $\begin{array}{l}\text { Has no functional } \\
\text { limitation or disability }\end{array}$ & $\begin{array}{l}\text { Has no functional } \\
\text { limitation or disability }\end{array}$ & .149 \\
\hline & & $\begin{array}{l}\text { Has functional limitation } \\
\text { or disability }\end{array}$ & .279 \\
\hline & $\begin{array}{l}\text { Receives income from } \\
\text { work or pension }\end{array}$ & Receives income & .135 \\
\hline & & Receives no income & .203 \\
\hline & Lives with spouse & Lives with spouse & .137 \\
\hline & & $\begin{array}{l}\text { Does not live with } \\
\text { spouse }\end{array}$ & .236 \\
\hline
\end{tabular}


The lower part of Table 6 shows probabilities for those who do not live with a child at either Wave 1 or 2 , hence the probabilities here represent the chances of changing living situations and moving in with a child. Functional health has the greatest net effect, nearly doubling the chances of moving in with a child from .149 among those remaining functionally healthy to .279 among those becoming functionally limited. Loss of income increases the chances of a transition to coresiding with a child from .135 to .203, and loss of a spouse increases the chances from .137 to .236 .

\section{DISCUSSION}

We began by suggesting that the fertility decline in China over the last several decades, coupled with changes in socioeconomic structure, has led to concern that traditional sources of familial support for the elderly will dissipate. This concern is based on the belief that older adults receive support in large part from adult children who coreside with their older parents, and that fewer children will mean lower rates of coresidence. Using data from the Beijing municipal area, we examined whether coresidence rates declined over the five-year period between 1992 and 1997, and pinpointed determinants of coresidence at a given point in time and transitions in coresidence using three waves of panel data. Our approach suggested that coresidence is determined by a set of characteristics representing availability of and need for support, as well as other demographic characteristics.

By 1997 the older adults in our sample were less likely to be living with their adult children than they were in 1992 . Still, coresidence rates remained high at nearly 60 percent. The decline was also found to be of borderline significance once account was taken of confounding changes in sample characteristics. Most probably, increasing age appears to be associated with declining rates of coresidence: older age among parents means that children are also older and may be more likely to marry and set up independent residences. Thus, the aging of the sample explains some of the unadjusted decline in coresidence. Still, a slight decline is noteworthy given the very short duration of the current study.

Our analysis of the determinants of coresidence with children suggested that factors related to the needs of older adults are highly associated with the chances of coresiding, with those in greater need being most likely to coreside. We found that older adults who have some formal education, who earn an income from work or a pension, and who had occupations throughout their lives that could be categorized as not involving heavy labor were less likely to be living with children and less likely to change coresidence status. Having functional limitations, that is, being unable to perform tasks necessary for daily living, greatly increases the probability of coresiding with a child and the probability of moving in with a child. In contrast, having a chronic condition was not strongly associated with coresidence.

We detected no linear association between number of living children and the probability of coresidence. Instead, we found that having two children as opposed to one 
was a critical threshold. In one sense, this finding may have deleterious implications, given China's policy of strongly discouraging having more than one child. Although the current generation of older adults, including those in our sample, may have any number of children, older adults belonging to future generations are more likely to have only one or at most two, hence rates of coresidence may decline. But there are other interpretations as well. Given the changes taking place in the socioeconomic structure of China, future generations of older adults are likely to have improved socioeconomic standing, which may also reduce the need for coresidence.

Our findings for rates at which changes in coresidence occur are in one way contrary to those of Frankenburg et al. (2002) for Indonesia, Singapore, and Taiwan; they found transitions into coresidence to be more frequent than transitions out of coresidence. In our sample, for instance, about 14 percent of elderly parents not coresiding in 1992 and 1994 had moved in with a child by 1997, while about 17 percent of those coresiding in the earlier two years had moved out of the coresidence arrangement by 1997 . Given that coresidence tends to decrease with age, the aging of the sample over the five years partly accounts for this finding. At the same time, we found that almost one-third of our sample changed coresidence status at some point between 1992 and 1997, suggesting a high rate of movement among our sample of older Chinese.

Multivariate analyses of these multi-wave transitions suggested that changes in need trigger changes in coresidence with children. For instance, we found that adults who had no functional limitations at Wave 1 but had such limitations at Wave 2 were much more likely to move from not living with a child to living with a child than were those who remained without functional limitations. This finding in particular lends support to our understanding of filial support within the Chinese family. That is, adult children are responsible for the older generation's well-being. Physical support, unlike material support, must be provided at close proximity, and moving in with a parent who cannot perform necessary daily functions is an appropriate way of attending to that parent's needs. The finding also suggests that reductions in family size may not result in a complete abandonment of those members of the older generation who have the greatest need. And it casts a measure of doubt on modernization perspectives that assume wholesale changes in family structure accompany socioeconomic development (Goode 1963; Levy 1966). We have found that abandonment of traditional living arrangements is progressing very slowly in China, while at the same time families continue to care for the older generation.

Similarly, changes in coresidence with a spouse and in income result in expected changes in coresidence with children. Logan et al. (1998) showed widowhood to be highly associated with coresidence at a fixed point in time, a finding that is supported by our results. Clearly, the loss of a spouse, who may be the single most frequent provider of support, raises an older adult's level of need.

One curious finding is that parents with sons were less likely to experience a change in coresidence. Perhaps the existence of a son means that support is more likely being 
provided from a distance, decreasing the need to be in a coresident arrangement. Yet, this finding is in contrast to that of Logan et al. (1998), who noted that elderly individuals with at least one son living in the urban areas of Shanghai and Tianjin are more likely to coreside with a child. In any case, research has shown that a preference for sons still exists within the Chinese family (Logan and Bian 1999).

What does our study add to the debate over the possibility of declining support for older adults in China as population aging continues in that country? We see some influence of declining family size on the provision of support and suggest that a two-child maximum would be a reasonable policy response. However, our findings suggest, as well, that changes in other socioeconomic and demographic characteristics, many of which are also in flux in China, may have effects that are much greater than the effect of a reduction in family size alone. The future may bring greater levels of rural-to-urban migration. Levels of education are increasing, and this tends to reduce the need for support while increasing the desire for independence. China is also likely to undertake wide-ranging reform of pension systems that might influence older adults in unforeseen ways.

For the time being, and contrary to some previous literature suggesting a deteriorating situation for older adults in China (for instance, Du and Guo 2000), our results suggest that family support structures for the elderly, when they are facilitated through coresidence, remain basically intact, particularly for those who require the greatest amount of support. This point suggests that there is a close link between the presence of a child in the household and the quality and quantity of support being provided to older adults. As Hermalin (1995) aptly notes, "coresidence in itself may not mean an active or substantial level of support of the elderly. Conversely, older parents living alone may still have frequent contact and receive substantial support from their children" (p. 5). At the same time, socioeconomic development may provide adult children with a greater array of resources at their disposal in the form of money, knowledge, and access to health care, resources that may be used to assist in the support of aging parents without the proximity afforded by coresidence. Coresidence has commonly been used as a proxy for old-age support in studies in the developing world, partly owing to the availability of household roster data from social surveys. But further assessment is required to elucidate the effects of availability, need, and demographic characteristics on the provision of support regardless of coresidence status.

\section{REFERENCES}

Albert, Stephen M. and Maria G. Cattell. 1994. "Family relationships of the elderly: Living arrangements." Pp. 85-107 in Old Age in Global Perspective: Cross-Cultural and CrossNational Views. New York: G.K. Hall \& Co.

Anh, Truong Si, Bui The Cuong, Daniel Goodkind, and John Knodel. 1997. "Living arrangements, partilineality and sources of support among elderly Vietnamese." Asia-Pacific Population Journal 12:69-88. 
Asis, Maruja Milagros B., Lita Domingo, John Knodel, and Kalyani Mehta. 1995. "Living arrangements in four Asian countries: A comparative perspective." Journal of CrossCultural Gerontology 10:145-162.

Banister, Judith. 1990. "Implications of the aging of China's population.” Pp. 268-308 in Changing Family Structure and Population Aging in China: A Comparative Approach, edited by Y. Zeng, C. Zhang, and S. Peng. Beijing: Peking University Press.

Bian, Fuqin, John R. Logan, and Yanjie Bian. 1998. "Intergenerational relations in urban China: Proximity, contact and help to parents." Demography 35:115-124.

Bongaarts, John and Zachary Zimmer. 2002. "Living arrangements of the elderly in the developing world: An analysis of DHS household surveys." Journal of Gerontology: Social Sciences 57:S145-S157.

Brown, Joseph Winchester, Jersey Liang, Neal Krause, Hiroko Akiyama, Hidehiro Sugisawa, and Taro Fukaya. 2002. "Transitions in living arrangements among elders in Japan: Does health make a difference?” Journal of Gerontology: Social Sciences 57:S209-S220.

Budak, Mary-Anne E., Kao-Lee Liaw, and Hiroshi Kawabe. 1996. "Co-residence of household heads with parents in Japan: A multivariate explanation." International Journal of Population Geography 2:133-152.

Cameron, L. 2000. "The residency decision of elderly Indonesians: A nested logit analysis." Demography 37:17-27.

Casterline, John B., Lindy Williams, Albert Hermalin, M.C. Chang, Napaporn Chayovan, Paul Cheung, Lita Domingo, John Knodel, and Mary Beth Ofstedal. 1991. "Differences in the living arrangements of the elderly in four Asian countries: The interplay of constraints and preferences." Comparative study of the elderly in Asia research reports No. 91-10. Ann Arbor: Population Studies Center, University of Michigan.

Chan, Angelique. 1997. "An overview of the living arrangements and social support exchanges of older Singaporeans." Asia-Pacific Population Journal 12:35-50.

Cheung, Fernando Chiu-Hung. 1988. "Implications of the one-child family policy on the development of the welfare state in the People's Republic of China." Journal of Sociology and Social Welfare 15:5-25.

Choi, Sung-Jae. 2000. "Ageing in Korea: Issues and policies.” Pp. 223-242 in Ageing in the AsiaPacific Region: Issues, Policies and Future Trends, edited by D. R. Phillips. New York: Routledge.

Cowgill, Donald O. and Lowell D. Holmes (Eds.). 1972. Aging and Modernization. New York: Meredith Organization.

Crimmins, Eileen M. and Yasuhiko Saito. 1993. "Getting better and getting worse: Transitions in functional status among older Americans." Journal of Aging and Health 5:3-36. 
DaVanzo, Julie and Angelique Chan. 1994. "Living arrangements of older Malaysians: Who coresides with their adult children?" Demography 31:95-113.

Department of Social Medicine. 1995. "Report of the Beijing Multidimensional Longitudinal Study on Aging." Beijing Geriatric Clincal and Research Center, Beijing.

De Vos, Susan. 1998. "Regional differences in living arrangements among the elderly in Ecuador." Journal of Cross-Cultural Gerontology 13:1-20.

De Vos, Susan. 1990. "Extended family living among older people in six Latin American countries.” Journal of Gerontology: Social Sciences 45:87-94.

Du, Peng and Zhi-Gang Guo. 2000. "Population aging in China." in Ageing in the Asia-Pacific Region: Issues, Policies and Future Trends, edited by D. R. Phillips. New York: Routledge.

Ebrey, Patricia Buckley. 1996. China. New York: Cambridge University Press.

Frankenberg, Elizabeth, Angelique Chan, and Mary Beth Ofstedal. 2002. "Stability and change in living arrangements in Indonesia, Singapore, and Taiwan, 1993-1999.” Population Studies 56:201-213.

Fricke, T., J.S. Chang, and L.S. Yang. 1994. "Historical and ethnographic perspectives on the Chinese family." Pp. 22-48 in Social Change and the Family in Taiwan, edited by A. Thornton and H.-S. Lin. Chicago: University of Chicago Press.

Goode, William J. 1963. World Revolution and Family Patterns. Glencoe, IL: Free Press.

Gui, Shixun. 2001. "Care of the elderly in one-child families in China: Issues and measures." in Elderly Chinese in Pacific Rim Countries: Social Support and Integration, edited by I. Chi, N. L. Chappell, and J. Lubben. Hong Kong: Hong Kong University Press.

Hashimoto, Akiko. 1991. "Living arrangements of the aged in seven developing countries: A preliminary analysis.” Journal of Cross-Cultural Gerontology 6:359-381.

Hermalin, Albert I. 1995. "Aging in Asia: Setting the research foundation.” Asia-Pacific Population Research Reports, No. 4. Honolulu: East-West Center.

Hermalin, Albert I. and Lora G. Myers. 2002. "Aging in Asia: Facing the crossroads." Pp. 1-24 in The Well-Being of the Elderly in Asia: A Four-Country Comparative Study, edited by A. I. Hermalin. Ann Arbor: University of Michigan Press.

Hermalin, Albert I., Mary Beth Ofstedal, and Ming-Cheng Chang. 1996. "Types of supports for the aged and their providers in Taiwan." Pp. 400-437 in Aging and Generational Relations Over the Life Course: A Historical and Cross-Cultural Perspective, edited by T. Hareven. New York: Walter de Gruyter.

Huisman, Martijn, Anton E. Kunst, and Johan P. Mackenbach. 2003. "Socioeconomic inequalities in morbidity among the elderly: A European overview." Social Science and Medicine 57:861-873. 
Jiang, Jingmei, Zhe Tang, Xiang Jun Meng, and Makoto Futatsuka. 2002. "Demographic determinants for change in activities of daily living: A cohort study of the elderly people in Beijing." Journal of Epidemiology 12:280-286.

Jiang, Zhenghua and Lingguang Zhang. 2000. "Fertility decline and population policy in China." Pp. 195-225 in Low Fertility and Policy Responses to Issues of Ageing and Welfare. Seoul: Korea Institute of Health and Social Affairs and United Nations Population Fund.

Jones, Gavin W. 1993. “Consequences of rapid fertility decline for old-age security.” Pp. 275-296 in The Revolution in Asian Fertility -Dimensions, Causes, and Implications, edited by R. Leete and I. Alam. Oxford: Clarendon Press.

Katz, S., A.B. Ford, R.W. Moskowitz, B.A. Jackson, and M.W. Jaffee. 1963. "Studies of illness in the aged: The index of ADL, a standardized measure of biological and psychosocial function." Journal of the American Medical Association 185:914-919.

Kim, Ik Ki, Jersey Liang, Ka-Oak Rhee, and Cheong-Seok Kim. 1996. "Population aging in Korea: Changes since the 1960s." Journal of Cross-Cultural Gerontology 11:369-388.

Kim, Cheong-Seok and Ka-Oak Rhee. 1999. "Living arrangements in old age: Views of elderly and middle aged adults in Korea." Hallym International Journal of Aging 1:94-111.

Knodel, John, Napaporn Chayovan, and Siriwan Siriboon. 1992. "The impact of fertility decline on familial support for the elderly: An illustration from Thailand." Population and Development Review 18:79-103.

Knodel, John and Nibhon Debavalya. 1997. "Living arrangements and support among the elderly in South-East Asia: An introduction." Asia-Pacific Population Journal 12:5-16.

Knodel, John and Mary Beth Ofstedal. 2002. "Patterns and determinants of living arrangements." Pp. 143-184 in The Well-Being of the Elderly in Asia: A Four-Country Comparative Study, edited by A. I. Hermalin. Ann Arbor: University of Michigan Press.

Lee, Yean-Ju and Zhenyu Xiao. 1998. "Children's support for elderly parents in urban and rural China: Results from a national survey." Journal of Cross-Cultural Gerontology 13:39-62.

Leung, Joe C.B. 1997. "Family support for the elderly in China: Issues and challenges." Journal of Aging and Social Policy 9:87-101.

Levy, Marion J. 1966. Modernization and the Structure of Societies. Princeton, NJ: Princeton University Press.

Lin Jiang. 1994. "Parity and security: A simulation study of old-age support in rural China." Population and Development Review 20:423-448.

Link, Bruce G. and Jo Phelan. 1995. "Social conditions as fundamental causes of disease." Journal of Health and Social Behavior Extra issue:80-94. 
Logan, John R. and Fuqin Bian. 1999. "Family values and coresidence with married children in urban China." Social Forces 77:1253-1282.

Logan, John R., Fuqin Bian, and Yanjie Bian. 1998. "Tradition and change in the urban Chinese family: The case of living arrangements." Social Forces 76:851-882.

Maeda, Daisaku and Yutaka Shimizu. 1992. "Family support for elderly people in Japan.” Pp. 235249 in Family Support for the Elderly: The International Experience, edited by H. L. Kendig, A. Hashimoto, and L. C. Coppard. New York: Oxford University Press.

Martin, Linda G. 1990. "Changing intergenerational family relations in East Asia." Annals of the American Academy of Political and Social Science 510:102-114.

Martin, Linda G. 1989. "Living arrangements of the elderly in Fiji, Korea, Malaysia, and the Philippines." Demography 26:627-643.

Martin, Linda G. 1988. “The aging of Asia.” Journal of Gerontology 43:99-113.

Mason, Karen Oppenheim. 1992. "Family change and support of the elderly in Asia: What do we know?” Asia-Pacific Population Journal 7:13-32.

Natividad, Josefina N. and Grace T. Cruz. 1997. "Patterns in living arrangements and familial support for the elderly in the Philippines." Asia-Pacific Population Journal 12:17-34.

Pei, Xiaomei and Vijayan K. Pillai. 1999. "Old age in China: The role of the state and the family." International Journal of Aging and Human Development 49:197-212.

Phillips, David R. 2000. "Ageing in the Asia-Pacific region: Issues, policies and contexts.” Pp. 1-34 in Ageing in the Asia-Pacific Region: Issues, Policies and Future Trends, edited by D. R. Phillips. New York: Routledge.

Poston, Dudley L., Jr. and Charles Chengrong Duan. 2000. "The current and projected distribution of the elderly and eldercare in the People's Republic of China." Journal of Family Issues 21:714-732.

Preston, Samuel H. and Paul Taubman. 1994. "Socioeconomic differences in adult mortality and health status." in Demography of Aging, edited by L. G. Martin and S. H. Preston. Washington, DC: National Academy Press.

Siriboon, Siriwan and John Knodel. 1994. "Thai elderly who do not reside with their children." Journal of Cross-Cultural Gerontology 9:21-38.

Sokolovsky, Jay. 2001. "Living arrangements of older persons and family support in less developed countries." Pp. 162-192 in Living Arrangements of Older Persons: Critical Issues and Policy Responses. New York: United Nations.

Tang, Zhe, Hui-Xin Wang, Chen Meng, Xiao-Guang Wu, Kjerstin Ericsson, Bengt Winblad, and Jin-Jing Pei. 1999. "The prevalence of functional disability in activities of daily living among elderly Beijing Chinese." Archives of Gerontology and Geriatrics 29:115-125. 
Treas, Judith and Jieming Chen. 2000. "Living arrangements, income pooling and the life course in urban Chinese families." Research on Aging 22:238-262.

United Nations. 2002. World Population Ageing 1950-2050. New York: United Nations.

Weinstein, M., T.H. Sun, M.C. Chang, and R. Freedman. 1994. "Co-residence and other ties linking couples and their parents." Pp. 305-334 in Social Change and the Family in Taiwan, edited by A. Thornton and H.-S. Lin. Chicago: University of Chicago Press.

Whyte, Martin King. 2003. "China's revolutions and intergenerational relations." Pp. 3-32 in China's Revolutions and Intergenerational Relations, edited by M. K. Whyte. Ann Arbor: University of Michigan Press.

Whyte, Martin King. 1997. "The fate of filial obligations in urban China." The China Journal 38:131.

Whyte, Martin King and Xu Qin. 2003. "Support for aging parents from daughters versus sons.” Pp. 167-195 in China's Revolutions and Intergenerational Relations, edited by M. K. Whyte. Ann Arbor: University of Michigan Press.

Yan, Shengming, Jieming Chen, and Shanhua Yang. 2003. "Living arrangements and old-age support.” Pp. 143-163 in China's Revolutions and Intergenerational Relations, edited by M. K. Whyte. Ann Arbor: University of Michigan Press.

Yan, Shengming and Iris Chi. 2001. "Living arrangements and adult children's support for the elderly in the new urban areas of Mainland China." Pp. 201-220 in Elderly Chinese in Pacific Rim Countries: Social Support and Integration, edited by I. Chi, N. L. Chappell, and J. Lubben. Hong Kong: Hong Kong University Press.

Yuan, Fang. 1990. "Support for the elderly: The Chinese way." Pp. 341-358 in Changing Family Structure and Population Aging in China: A Comparative Approach, edited by Y. Zeng, C. Zhang, and S. Peng. Beijing: Peking University Press.

Zeng Yi. 1990. "An analysis of changing trends in China's urban and rural households." Chinese Journal of Population Science 2:187-199.

Zeng Yi. 1986. "Changes in family structure in China: A simulation study." Population and Development Review 12:675-703.

Zeng Yi and Linda K. George. 2001. "Extremely rapid ageing and the living arrangements of the elderly: The case of China." The Population Bulletin of the United Nations. Living Arrangements of Older Persons: Critical Issues and Policy Responses Special Issues:255287.

Zeng Yi, James W. Vaupel, Xiao Zhenyu, Zhang Chunyuan, and Liu Yuzhi. 2002. "Sociodemographic and health profiles of the oldest old in China." Population and Development Review 28:251-273. 
Zimmer, Zachary and Sovan Kiry Kim. 2001. "Living arrangements and sociodemographic conditions of older adults in Cambodia." Journal of Cross-Cultural Gerontology 16:353381 .

Zimmer, Zachary and Julia Kwong. 2003. "Family size and support of older adults in urban and rural China: Current effects and future implications." Demography 40:23-44. 


\section{POLICY DIVISION WORKING PAPERS}

If still in print, single copies of up to three working papers from 1989 through 2003 are available free of charge.

Beginning with the 2004 issues, the working papers will no longer be available in print format. Instead they will be distributed electronically. As each new paper is completed subscribers will be notified by e-mail and a link to the paper will be provided.

To subscribe to the Policy Research Division working paper e-mail notification list, or to obtain back issues from 1989 to 2003, please send your request to prdwp@popcouncil.org.

PDFs of recent issues are available at www.popcouncil.org/publications/wp/prd/rdwplist.html

2004

187

Zachary Zimmer, Xianghua Fang,

Toshiko Kaneda, Zhe Tang, and

Julia Kwong, "Trends and

transitions in children's

coresidence with older adults in

Beijing municipality."

186 Sajeda Amin and Alaka M. Basu.

"Popular perceptions of emerging

influences on mortality and

longevity in Bangladesh and West

Bengal."

185 John Bongaarts. "Population aging and the rising cost of public pensions."

184 Mark R. Montgomery and Paul C. Hewett. "Urban poverty and health in developing countries: Household and neighborhood effects."

2003

183 Agnes R. Quisumbing and Kelly Hallman. "Marriage in transition: Evidence on age, education, and assets from six developing countries."
182 Paul C. Hewett, Barbara S.

Mensch, and Annabel S. Erulkar, "Consistency in the reporting of sexual behavior among adolescent girls in Kenya: A comparison of interviewing methods."

181 Zachary Zimmer, Linda G. Martin, and Hui-Sheng Lin, "Determinants of old-age mortality in Taiwan."

180 Frank K. Nyonator, J. Koku Awoonor-Williams, James F. Phillips, Tanya C. Jones, and Robert A. Miller, "The Ghana Community-based Health Planning and Services Initiative: Fostering evidence-based organizational change and development in a resourceconstrained setting."

179 John Bongaarts and Griffith Feeney, "Estimating mean lifetime."

\footnotetext{
* No longer available as a printed publication. Download electronic file from Web site only.
} 
178 Elizabeth F. Jackson, Patricia Akweongo, Evelyn Sakeah, Abraham Hodgson, Rofina Asuru, and James F. Phillips, "Women's denial of having experienced female genital cutting in northern Ghana: Explanatory factors and consequences for analysis of survey data."

177 John Bongaarts, "Completing the fertility transition in the developing world: The role of educational differences and fertility preferences."

176 Cynthia B. Lloyd and Paul C. Hewett, "Primary schooling in sub-Saharan Africa: Recent trends and current challenges."

175 James F. Phillips, Tanya C. Jones, Frank K. Nyonator, and Shruti Ravikumar, "Evidence-based development of health and family planning programs in Bangladesh and Ghana."

174 Geoffrey McNicoll, "Population and development: An introductory view."

173 Paul Demeny, "Population policy: A concise summary."

172 Zachary Zimmer, Napaporn Chayovan, Hui-Sheng Lin, and Josefina Natividad, "How indicators of socioeconomic status relate to physical functioning of older adults in three Asian societies."

171 Sajeda Amin and Nagah H. AlBassusi, "Wage work and marriage: Perspectives of Egyptian working women."
170 Ravai Marindo, Steve Pearson, and John B. Casterline, "Condom use and abstinence among unmarried young people in Zimbabwe: Which strategy, whose agenda?"

169 Zachary Zimmer and Julia Dayton, "The living arrangements of older adults in sub-Saharan Africa in a time of HIV/AIDS."

168 Paul C. Hewett, Annabel S. Erulkar, and Barbara S. Mensch, "The feasibility of computerassisted survey interviewing in Africa: Experience from two rural districts in Kenya."

2002

167* Dominic K. Agyeman and John B. Casterline, "Social organization and reproductive behavior in southern Ghana."

166* Carol E. Kaufman and Stavros E. Stavrou, "Bus fare, please': The economics of sex and gifts among adolescents in urban South Africa."

165 Kelly Hallman, Agnes R. Quisumbing, Marie Ruel, and Bénédicte de la Brière, "Childcare, mothers' work, and earnings: Findings from the urban slums of Guatemala City."

164 Cynthia B. Lloyd, Cem Mete, and Zeba A. Sathar, "The effect of gender differences in primary school access, type, and quality on the decision to enroll in rural Pakistan."

* No longer available as a printed publication. Download electronic file from Web site only. 
163 Barbara S. Mensch, Wesley H. Clark, and Dang Nguyen Anh, "Premarital sex in Vietnam: Is the current concern with adolescent reproductive health warranted?"

162 Naomi Rutenberg, Carol E. Kaufman, Kate Macintyre, Lisanne Brown, and Ali Karim, "Pregnant or positive: Adolescent childbearing and HIV risk in South Africa."

161 John Bongaarts, "The end of the fertility transition in the developing world."

160* Julia Dayton and Martha Ainsworth, "The elderly and AIDS: Coping strategies and health consequences in rural Tanzania."

159 Carol E. Kaufman, Shelley Clark, Ntsiki Manzini, and Julian May, "How community structures of time and opportunity shape adolescent sexual behavior in South Africa."
158 Geoffrey McNicoll, "Demographic factors in East Asian regional integration."

157 Zachary Zimmer and Sovan Kiry Kim, "Living arrangements and socio-demographic conditions of older adults in Cambodia."

156 John Bongaarts and Griffith Feeney, "How long do we live?"

155 Zachary Zimmer, Linda G. Martin, and Ming-Cheng Chang, "Changes in functional limitations and survival among the elderly in Taiwan: 1993, 1996, and 1999."

\footnotetext{
* No longer available as a printed publication. Download electronic file from Web site only.
} 